\title{
Homenagem
}

\section{A contribuição de Victor Valla ao pensamento da educação popular}

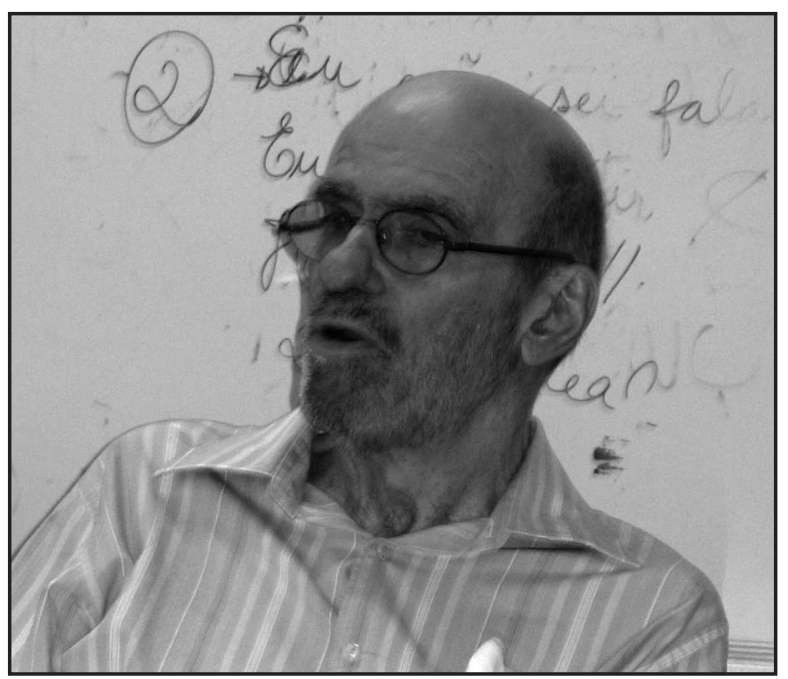

Em setembro de 2009, faleceu Victor Vicent Valla, educador e pesquisador norte-americano residente no Rio de Janeiro, que veio para o Brasil em 1964 e marcou o campo da educação popular com importantes contribuições teóricas e organizativas. Foi, antes de tudo, uma pessoa indignada com a pobreza latino-americana e fascinada com suas potências de criação, alegria, conhecimento e proposição política. Investiu grande parte de seu esforço na tentativa de compreensão dos diferentes caminhos da busca de ser mais das classes populares, com quem a cultura erudita costuma ter tanto desprezo. Participou ativamente do
Grupo de Trabalho Educação Popular da Associação Nacional de Pós-Graduação e Pesquisa em Educação (ANPEd), durante duas décadas, marcando fortemente o seu modo de funcionamento e a sua identidade. Em 2007, esse grupo de trabalho colocou como prioridade de estudo a compreensão de sua contribuição para a educação popular, encomendando um trabalho para pesquisadores que conviveram mais de perto com suas atividades acadêmicas: Maria Tereza Goudart Tavares, Reinaldo Matias Fleuri, Eveline Bertino Algebaile e Eymard Mourão Vasconcelos. O próprio Victor Valla, depois de provocado, concordou em participar dessa avaliação crítica de sua obra. Essas reflexões, apresentadas na 30ª Reunião Anual da ANPEd, estão sendo publicadas nesse número em sua homenagem. Trata-se de um texto, com diferentes análises sobre a contribuição de Victor Valla ao pensamento da educação popular, que procurou responder a algumas questões: o que há na sua produção teórica e no seu modo de gerir as relações acadêmicas que possibilitou tão grande impacto de suas contribuições? Que impactos são esses? Além de sua competente atuação acadêmica e de seu posicionamento sempre contrário às injustiças sociais que ainda marcam nosso país, Valla será lembrado por ter sido sempre um homem generoso, íntegro e leal. 


\section{O intelectual, o professor, o militante: um encontro com o pensamento de Victor Valla}

\author{
Maria Tereza Goudart Tavares \\ Universidade do Estado do Rio de Janeiro, \\ Faculdade de Formação de Professores
}

Aprendo mais com abelhas do que com aeroplanos. É um olhar para baixo que eu nasci tendo. É um olhar para o ser menor, para o insignificante que eu me criei tendo. O ser que na sociedade é chutado como uma barata - cresce de importância para o meu olho. Ainda não entendi por que herdei esse olhar para baixo. Sempre imagino que venha de ancestralidades machucadas. Fui criado no mato e aprendi a gostar das coisinhas do chão - antes que das coisas celestiais. Pessoas pertencidas de abandono me comovem. Tanto quanto as soberbas coisas infimas.

Manoel de Barros (2001, p. 27)

Inspirada por Manoel de Barros e tantos outros que não apartam vida e trabalho em seus processos de produção teórico-prática e pela reflexão sobre as coisas do mundo, busco neste breve texto tecer algumas reflexões sobre meu encontro ${ }^{1}$ com o pensamento de Victor Vincent de Valla: professor querido, intelectual inspirador e militante combativo da educação popular como ferramenta de luta política e de (auto)conhecimento. Escrever sobre esse encontro implica, porém, reconstruir alguns movimentos de meus percursos pessoais e profissionais, sobretudo no "mundo da escola”, dos quais venho atualizando há mais de vinte anos o meu inconformismo e a busca de compreensão das razões e implicações da histórica improdutividade produtiva da escola pública no país, bem como o fracasso escolar impingido às crianças das classes

${ }^{1}$ Para Deleuze (1996, p. 14), “Tudo é apenas encontro no universo, bom ou mau encontro". Para esse autor, encontram-se pessoas (e às vezes sem as conhecer bem, nem jamais tê-las visto), mas também movimentos, ideias, acontecimentos, entidades. Nesse sentido, depois de quase duas décadas, alegra-me poder escrever sobre meu bom encontro com o pensamento e a pessoa que é Victor Valla. populares, principalmente nas favelas e periferias urbanas do estado do Rio de Janeiro.

O exercício da memória leva-me ao passado, ao tempo-espaço afetivo de meu segundo encontro com Valla, em outubro de 1987, ${ }^{2}$ na Universidade Federal Fluminense, no $5^{\circ}$ andar da Faculdade de Educação o "Olimpo" - como diziam alguns dos companheiros do Programa de Pós-Graduação em Educação. Ainda guardo na memória as fartas lembranças de minha entrevista (última etapa do processo seletivo ao mestrado), realizada por Valla e Regina Leite Garcia.

Apesar de meu nervosismo e de toda a tensão preliminar do contexto, a própria entrevista já antecipava o meu privilégio (como aluna) de uma convivência intelectual generosa e instigadora. Uma convivência marcadamente dialógica, pautada no desafio de tentar construir muito mais entendimentos das coisas, dos fenômenos, das relações que nos cercam/atravessam do que propriamente explicações teóricas para esses fenômenos.

Desse modo, em nossos encontros semanais, todas as terças-feiras, de 1988 na disciplina Tópicos Especiais de Educação Popular, aprendíamos sobretudo com o jeito manso e sábio do professor Valla, a pensar e fazer pensar. Aprendíamos que a experiência do pensamento não é doação caridosa, e sim trabalho de ação e reflexão sobre as coisas que se pensa e, principalmente, sobre as coisas que se faz.

Nessa intensa relação professoral, minha aprendizagem fundamental (construída entre silêncios, falas econômicas e muita "escuta sensível”) foi que ensinar é um dar e prestar. Mas o que no ensino se dá e se presta não são apenas conteúdos, teorias, informações. São condições e ferramentas para aprender a pensar, pensando-nos: a nós próprios e a vida que nos atravessa.

No meu caderno de anotações das aulas, muitas questões, muitos exercícios de pensamentos: O que é

${ }^{2}$ Segundo encontro e primeiro principalmente, pois embora não o conhecesse já tinha me encontrado com Victor Valla, intelectual inspirador, no livro Educação e favela, organizado por ele em 1986, fundamental na minha trajetória pessoal-profissional. 
a educação popular? O que torna a educação popular? Contra quem, a favor de quem é feita a educação popular? Afinal, é possível uma educação popular?

Questões nodais de natureza política e epistêmica que hoje, vinte anos depois, ainda são inspiradoras do diálogo de pensamento e matéria-prima de muitos trabalhos em nosso GT.

Aprendi com Valla que a educação popular nunca foi pensada para a população brasileira como um todo, mas para "aquele segmento que hoje se conhece como camadas populares e com as formas de educação que se desenvolvem para, ou com, essas camadas” (Valla, 1986, p. 11).

Ouvindo, lendo e dialogando com ele aprendi também que:

\begin{abstract}
Não queremos desprezar a possibilidade de a educação popular ser um fator de transformação da sociedade, mas ao mesmo tempo queremos desvincular as "intenções e desejos" dos agentes de educação popular de uma obrigatória transformação social. Não achemos que a educação popular, por si mesma, traga necessariamente no seu bojo as sementes da transformação social. A nosso ver, trata-se de uma questão que inclui variáveis tais como a conjuntura política econômica, a organização dos educandos em questão e a sensibilidade política e cultural dos agentes. (idem, ibidem, p. 16)
\end{abstract}

Essa aprendizagem conceitual e vivencial ${ }^{3}$ possibilitou-me a compreensão da educação popular como um campo de lutas, isto é, constituída e constituinte de relações sociais concretas, espaço de jogo de força e luta por hegemonia.

Em meu trabalho de educação popular nas creches comunitárias, pude compreender que no Rio de Janeiro, desde os anos de 1950, pelo peso numérico ou força política, tornou-se impossível ignorar o crescimento das favelas e dos bairros proletários. Paralelo a esse crescimento, o poder público sempre procurou formular estratégias visando conter a grande ameaça de favelização da cidade.

${ }^{3}$ Trabalhei durante uma década (1987-1997) nas favelas do Rio de Janeiro na assessoria às creches comunitárias.
Nessa perspectiva, o governo sempre alternou políticas de remoção, cooptação e urbanização que, independentemente do efeito demonstrativo provocado, procuravam escamotear as profundas contradições sociais geradas pelo sistema capitalista, particularmente pelo modelo político-econômico brasileiro.

Como a expansão do processo de favelização da cidade se dá também no imaginário social, ocorre a identificação simplista e ideológica (bastante irradiada pelos meios de comunicação) do favelado como "perigoso", desordeiro em potencial, que é preciso educar, lapidar a barbárie, educar para a civilidade, para a cidade.

Temerosos de que os do morro venham a "incomodar” os do asfalto (a geografia do Rio de Janeiro é singular, no sentido de que grande parte das favelas se situa em morros no coração da cidade, em áreas nobres, e não apenas na periferia), os governos vêm formulando estratégias na tentativa de amortecer os conflitos sociais, freando a demanda por serviços básicos através de intervenções (em geral descontínuas e fragmentadas) nas favelas.

Essas intervenções dizem respeito ao conjunto de práticas sociais, políticas e ideológicas que se manifestam na cidade em diferentes conjunturas históricas, diante da formulação e articulação de estratégias de controle social, tendo em vista os conflitivos e antagônicos interesses presentes numa sociedade tão hierarquizada e excludente como a nossa.

Paradoxalmente, nessa relação/intervenção constitutiva também de nossas práticas de assessoria às creches comunitárias, junto a educadoras, crianças, pais e representantes das associações de moradores, pude compreender, ajudada pelo vigoroso pensamento de Valla, nossa crise de interpretação ante as diferentes lógicas, comportamentos, demandas, práticas discursivas, enfim, modos de vida dos grupos denominados populares.

E novamente é o intelectual, professor e militante que me instiga a interrogar o meu fazer, o meu pensar:

Bastaria (aos intelectuais e às lideranças) conhecer a realidade dos grupos com que se relacionam para poder facilitar a transmissão, ou é necessário mais do que isso? A questão 
é facilitar, simplificar a mensagem ou é possibilitar a construção de um outro conhecimento, que é resultado de uma relação desigual entre as duas partes? (Valla, 1993, p. 34)

A problematização dessas questões (e de muitas outras) conduzem-me a outro bom encontro: com José de Souza Martins e a sua sociologia do estranhamento:

As ciências humanas, com possível exceção da Antropologia, não têm sido capazes de decifrar o silêncio daqueles que não foram eleitos pelo saber acadêmico como informantes, com efeito, válidos dos pesquisadores. (Martins, 1991, p. 55)

No campo político-epistemológico, na produção de conhecimento, se especialmente o contexto de pesquisa envolver os setores, os grupos subalternos (Martins, 1989), os pobres (Santos, 1997) e os oprimidos (Freire, 1974), o reconhecimento do outro é muito mais complexo e epistemologicamente difícil, pois hegemonicamente o pensamento científico brasileiro, a nossa intelectualidade (formada na mentalidade europeia) define esses sujeitos como carentes, lacunares, não somente no campo material como no campo simbólico.

Ao dialogar com Valla, entendi que essa forma de entendimento, ao simplificar a realidade, obscurece a sua compreensão, desafiando-nos a refletir criticamente sobre essa temática. Uma das hipóteses sobre as quais venho refletindo implica a perspectiva de que, no campo investigativo, no terreno da pesquisa educacional propriamente dita, temos dificuldade de reconhecer o outro, esse outro, porque não o enxergamos.

Nesse sentido, se continuarmos a compreender os setores populares, os subalternos, os pobres e a própria cultura da pobreza como lacunar, inferior, atrasada, antirracional, não os enxergaremos como legítimo outro, com um sistema diferente de viver, pensar, responder com outras lógicas os desafios colocados pela vida. Ao contrário de carente e/ou lacunar, incompleto, o/a outro/a poderia ser visto/a fundamentalmente como diferente, particular e genérico/a, capaz de interpretar e (re)inventar a vida no jogo dramático de sua vida cotidiana.

Esse pequeno texto, pretexto para dialogar com o pensamento de Victor Valla, não foi escrito com pretensões acadêmicas, problematizadoras. É, sobretudo, um preito de aluna atenta e dedicada, que há mais de vinte anos se nutre dessa generosa companhia intelectual. Assim, espero que as linhas escritas neste trabalho possam convidar com alegria e reflexividade à (re)leitura da obra de Victor Valla.

\section{Referências bibliográficas}

BARROS, Manoel. Retrato do artista quando coisa. Rio de Janeiro: Ricardo, 2001.

DELEUZE, Giles. Conversações. São Paulo: Editora 34, 1996.

FREIRE, Paulo. Pedagogia do oprimido. Rio de Janeiro: Paz e Terra, 1974.

MARTINS, José de Souza. Dilemas sobre as classes subalternas na idade da razão. $I n$ : Caminhada no chão da noite. São

Paulo: Hucitec, 1989.

O massacre dos inocentes: a criança sem infância no Brasil. São Paulo: Hucitec, 1991.

SANTOS, Milton. Técnica, espaço, tempo: globalização e meio técnico-científico informacional. São Paulo: Hucitec, 1997.

VALLA, Victor Vincent (Org.). Educação e favela. Petrópolis: Vozes, 1986.

. Participação popular e saúde: a questão da capacitação técnica no Brasil. In: VALLA, Victor V.; STOTZ, Eduardo N. (Orgs.). Participação popular, educação e saúde: teoria e prática. Rio de Janeiro: Relume Dumará, 1993.

\section{Victor Valla e a pesquisa militante}

\author{
Reinaldo Matias Fleuri \\ Universidade Federal de Santa Catarina, \\ Programa de Pós-Graduação em Educação
}

Conheci Victor Valla no início da década de 1990 quando, a seu convite, visitei a Escola Nacional de Saúde Pública, no Rio de Janeiro, para discutir com seu grupo de pesquisa as "relações de saber e poder na prática educativa”. A seguir, nossa amizade e parceria 
foram se aprofundando pela participação no Grupo de Trabalho Educação Popular da ANPEd. Compreendi, então, o seu interesse por entender os saberes elaborados pelas classes populares, que começou a ser compartilhado por esse grupo de pesquisadores no período em que Valla coordenou o GT Educação Popular (1990-1993). Sua atuação foi determinante para construir uma dinâmica de trabalho específica desse GT, caracterizada pela intensa capacidade de diálogo, ao mesmo tempo acolhedor e crítico. Esse clima de solidário debate científico favoreceu a ampliação e a consolidação do grupo, alimentando opções que determinaram seu foco de investigação durante toda a década de 1990.

Já em 1991, na $14^{a}$ Reunião Anual da ANPEd, em São Paulo, o grupo perguntou-se: até que ponto nos limitamos a reproduzir conhecimento, desprezando os processo de produção do saber presente na prática social? E defendeu a construção do conhecimento baseado na relação entre experiência e conhecimento, decidindo investigar mais particularmente a relação entre o conhecimento científico e o conhecimento produzido pelos setores populares organizados da sociedade civil.

Nessa direção, durante a $15^{\text {a }}$ Reunião Anual, em 1992, em Caxambu, o GT Educação Popular discutiu a função social do conhecimento, problematizando-o nas práticas de movimentos urbanos, de barragens e de saúde, assim como na formação de professores. Questionou-se a polaridade entre o científico e o popular, apontando para uma perspectiva multidisciplinar, ao compreender que o conhecimento científico transita em diferentes disciplinas, ao mesmo tempo em que se registra um movimento de negação da hierarquia de saberes. O debate levou a focalizar a questão metodológica em educação popular na reunião seguinte, em 1993. O grupo discutiu nessa ocasião a crise dos movimentos sociais e a emergência da nova ordem mundial. Discutiu também os pressupostos teóricos de educação popular e as implicações epistemológicas da metodologia (pesquisa-ação) utilizada na produção de conhecimento. Uma das questões interessantes que emergiram nesse debate foi a crise dos mediadores nas práticas de educação popular cujas manifestações culturais e formas de organização popular sugerem nostalgia de um passado irrecuperável e certa uniformidade e homogeneidade que nunca existiram nos movimentos de educação popular.

O debate sobre a metodologia da educação popular apontou para uma dimensão mais profunda dos problemas vividos nas práticas de mediação entre as instituições do Estado e os movimentos populares. As dificuldades de compreensão recíproca não decorrem apenas de problemas metodológicos, mas do próprio estatuto epistemológico das ciências e dos saberes populares, assim como da configuração das relações de poder que se tecem dinamicamente na sociedade como um todo. Na conjuntura política daquele período, esboroava-se o mito do governo centralizado a partir de um projeto único de sociedade (com a queda do Muro de Berlim). Paralelamente, em nível de elaboração científica, o modelo hegemônico de ciência estava sendo colocado em cheque pela multiplicidade e pela vitalidade de saberes que circulam na sociedade e interagem conflitualmente na constituição dos discursos de verdade. Se o Estado parecia não mais ser o ponto privilegiado para gerir a sociedade, a ciência estava sendo questionada como ponto de vista privilegiado para compreender a pluralidade dos conhecimentos produzidos socialmente.

Na construção desse debate historicamente situado, Valla teve papel determinante. Não só porque animou os participantes a investir esforços para reconstituir o GT Educação Popular e, assim, superar a crise de identidade e de coesão que o grupo atravessou no início da década de 1990. Mas, sobretudo, porque Valla trouxe um aporte teórico que se constituiu em fecundo eixo articulador do processo de investigação do grupo, ao problematizar a dificuldade que os profissionais e intelectuais têm para compreender o que as classes populares estão querendo lhes dizer. Para Valla, essa dificuldade está relacionada tanto com o preconceito de que as pessoas "humildes, pobres, moradoras da periferia” são incapazes de produzir um conhecimento válido e tomar iniciativas coerentes, quanto com a desconsideração da diversidade de 
grupos sociais, constituída a partir de diferentes raízes culturais e contextos sociais, que são entendidos sob o conceito de "classes subalternas".

O que se coloca em questão é a pressuposição de que "as ideias de uma época têm sua origem com as elites, as classes superiores, e de que sua difusão chega às classes subalternas de forma mecânica, sofrendo deterioração, sendo deformadas na medida em que são assimiladas pelas classes subalternas” (Ginzburg, 1987 apud Valla, 1994, p. 8). Nesse sentido, “a cultura popular dever ser pensada como cultura, como conhecimento acumulado, sistematizado, interpretativo e explicativo, e não como cultura barbarizada, forma decaída da cultura hegemônica, mera e pobre expressão do particular” (Martins, 1989, apud Valla, 1994, p. 10).

Mais propriamente, é preciso reconhecer as culturas populares, no plural, que constituem as diferentes formas de organização social e de interpretação da realidade construídas pelos diferentes grupos sociais que constituem as chamadas "classes subalternas". São culturas com representações sociais e visões de mundo específicas, elaboradas segundo lógicas e categorias próprias. Ao ignorá-las ou desqualificá-las, os intelectuais e operadores sociais correm o risco de não entendê-las, de invalidar esses saberes e reforçar a trama de poder que, em nossa sociedade, subjuga essas culturas.

O debate sobre a crise de compreensão a respeito das culturas e das formas de organização das classes populares coloca em foco questões relativas à cultura, à subjetividade, ao imaginário e às representações sociais, problematizando as concepções metodológicas e os pressupostos epistemológicos da educação popular, numa trajetória de ampliação e aprofundamento da elaboração teórica pelo GT ao longo da década de 1990. A discussão sobre o conhecimento na educação popular, colocada no GT em 1992, impulsiona em 1993 a crítica dos pressupostos epistemológicos da educação popular no contexto da crise de paradigmas e da emergência da nova ordem mundial. Introduz-se o referencial da hermenêutica para a análise da metodologia de educação popular. Tal discussão dos modelos de conhecimento enseja a tematização, em 1994, da crise de compreensão dos saberes das classes populares por parte dos mediadores em educação popular. Tal debate é alimentado com estudos da sociodinâmica, das representações sociais e do imaginário. Em 1995, aprofunda-se o debate sobre as relações de poder inerentes à elaboração e à relação entre saberes. Em 1996, formulam-se teorias capazes de permitir novas interpretações das relações de saber-poder nas formas emergentes de organização popular (como a teoria do apoio social, focalizada por Valla após seu estágio pós-doutoral nos EUA), ou na elaboração coletiva do conhecimento (como a sociopoética). Em 1997, a produção do Encontro de Intercâmbio do GT Educação Popular consolidou a crítica aos pressupostos epistemológicos da ciência e da educação popular e a perspectiva da complexidade veio contribuir para formulação das perspectivas teóricas emergentes nas propostas da teoria do apoio social e da sociopoética. Na reunião desse mesmo ano, sob a liderança de Valla, a colocação do tema da religiosidade popular ampliou os estudos que se vinham fazendo a respeito do apoio social na busca de entender as formas emergentes de organização popular. Tal linha de pesquisa foi reforçada pela retomada do enfoque das representações sociais e pela discussão dos padrões socioculturais populares. Em 1998, o aporte da teoria das configurações amplia o enfoque da teoria da complexidade na busca compreensão da diversidade/unidade de sentidos e dimensões da educação popular, nos diferentes campos e movimentos sociais.

Na 22a Reunião Anual, em 1999, dando continuidade à sua linha de pesquisa, Valla apresentou trabalho sobre A educação popular e saúde diante das formas alternativas de lidar com a saúde. Nesse trabalho, discute

\footnotetext{
[...] um questionamento que se difunde entre os profissionais de saúde: se a maneira como o atendimento de saúde se estrutura no Brasil é capaz de lidar com o que alguns chamam de “sofrimento difuso apresentado pelas classes populares”. A questão que se coloca não é se a saúde alternativa é um quebra-galho para a crise que se apresenta, mas se a própria crise não aponta para alternativas de lidar com os problemas
} 
de saúde da população. Quando se analisa o conteúdo da saúde alternativa nos jornais da grande imprensa, percebe-se que geralmente está se tratando de uma discussão dirigida aos leitores das classes média e alta. Dentro da perspectiva de uma educação popular transformadora, é necessário distinguir entre propostas de saúde alternativa "individualizantes” das classes média e alta e os caminhos coletivos das classes populares, criados a partir das suas condições de vida. (Valla, 1999, p. 244-245)

A proposta de investigação desenvolvida por Valla no contexto do GT Educação Popular assumiu uma perspectiva de pesquisa que desenvolveu um olhar a partir de dentro das relações sociais, a partir dos pontos de vista dos diferentes sujeitos em relação. Trata-se de uma perspectiva diferente das pesquisas que elaboram uma interpretação dos fenômenos sociais, a partir do alto (Gonsalves, 1999). A visão aérea é insuficiente para entender as emoções e o contexto que levam os sujeitos a viver determinada situação e a realizar certas opções. Daí a necessidade de ouvir e elaborar o ponto de vista de cada agente em relação. Daí o desafio, que enfrenta o pesquisador no campo da educação popular, de "manter os pés no chão e a cabeça nas nuvens".

Nessa perspectiva é que se articulam pesquisa “teórica” e pesquisa “militante”. Não como dois modelos de pesquisa distintos e contrapostos, mas como duas dimensões necessariamente inter-relacionadas no processo da pesquisa social. Toda pesquisa tem uma dimensão "teórica”, pois busca elaborar uma "visão" rigorosa e de conjunto sobre um fenômeno. Mas os fenômenos sociais são constituídos por diferentes sujeitos em relação. E o próprio pesquisador se coloca como um desses sujeitos em relação. O pesquisador interfere, pois, na configuração do próprio fenômeno objeto de sua pesquisa. Assim, a pesquisa no campo social só se torna radical, rigorosa e de conjunto na medida em que consegue, de um lado, elaborar e articular os pontos de vista dos diferentes sujeitos ("olhar de dentro") e, de outro, explicitar os significados construídos dinamicamente na interação desses pontos de vista ("olhar do alto").
Tal construção "teórica” torna-se possível na medida em que, "metodologicamente", o pesquisador se assume como um sujeito (com suas opções, seu contexto, suas emoções específicas) em relação com os outros sujeitos, junto aos quais desenvolve seu trabalho de pesquisa. Mas o resultado do trabalho do pesquisador pode interferir, sobretudo, na elaboração de práticas discursivas. Estas constituem campos de mediação a partir dos quais as pessoas se identificam com grupos ou se articulam em movimentos sociais, assumindo e implementando opções coletivas. Nisso reside uma das dimensões políticas importantes da pesquisa e da atividade cultural, que Valla soube tão bem elaborar.

Por isso, repetindo o posfácio à segunda edição do livro Travessia, em que Marisa Vorraber Costa e eu discutimos a trajetória do GT Educação Popular na década de 1990,

\section{[...] gostaria de manifestar ao companheiro Victor Vincent Valla nosso carinhoso reconhecimento por sua contribuição vital na história do Grupo de Trabalho Educação Popular. Sua perspicácia e seu brilhantismo intelectual, sua carinhosa atenção e solidariedade, sua criticidade e espiritualidade, seu compromisso político e sua persistência cotidiana no cuidado com as causas populares vêm constituindo e simbolizando o sentido profundo da vitalidade dos estudos e dos diálogos neste nosso grupo de pesquisa. (Fleuri \& Costa, 2005, p. 128)}

\section{Referências bibliográficas}

FLEURI, Reinaldo Matias; COSTA, Marisa Vorraber. Travessia: questões e perspectivas emergentes na pesquisa em educação popular. 2. ed. Ijuí: UNIJUí, 2005.

GINZBURG, Carlo. O queijo e os vermes: o cotidiano e as ideias de um moleiro perseguido pela Inquisição. São Paulo: Companhia das Letras, 1987.

GONSALVES, Elisa Pereira. Pesquisar, participar: sensibilidades (pós) modernas. In: REUNIÃO ANUAL DAANPEd, 22., Caxambu, 1999. Anais... Rio de Janeiro: Mundo Virtual, 1999. 1. CD-ROM.

MARTINS, José de Souza. Dilemas sobre as classes subalternas na idade da razão. In: Caminhada no chão da noite. São Paulo: HUCITEC, 1989. 
VALLA, Victor Vincent. A crise de interpretação é nossa: procurando compreender a fala das classes subalternas. In: REUNIÃO ANUAL DA ANPEd, 17., Caxambu, 1994. Anais... Rio de Janeiro: ANPEd, 1994. 1. CD-ROM.

. A educação popular e saúde diante das formas alternativas de lidar com a saúde. In: REUNIÃO ANUAL DA ANPEd, 22., Caxambu, 1999. Programa e Resumos. Caxambu: ANPEd, 1999. p. 244-245.

\section{Em Valla, reconhecimento e valorização, na pesquisa acadêmica, do jeito de produzir conhecimento da educação popular}

\author{
Eymard Mourão Vasconcelos \\ Universidade Federal da Paraíba, Programa \\ de Pós-Graduação em Educação
}

Conheci Victor Valla há 23 anos, em um curso que ministrou no mestrado em Educação da Universidade Federal de Minas Gerais. O interesse comum com as questões da educação popular no campo da saúde aproximou-nos desde logo. Há 15 anos passamos a investir juntos na construção da Rede de Educação Popular em Saúde, exigindo muitas articulações, encontros e conversas. Ele interessava-se muito por meu olhar de médico e sanitarista para as questões que o intrigavam. Desde então, a convivência quase anual nas reuniões da ANPEd, em que ficávamos sempre hospedados no mesmo quarto, possibilitou-me acompanhar muito de perto seu processo pessoal de elaboração teórica, com seus dilemas, descobertas e perplexidades. Foi um grande privilégio merecer essa amizade, cumplicidade e esse apoio de um pesquisador tão mais experiente. É desse lugar especial de proximidade afetiva e militante que proponho refletir sobre as suas contribuições para o campo da educação popular, pois me permite perceber dimensões não muito evidentes quando examinamos apenas seus textos.

Toda a produção profissional de Valla está marcada, de um lado, pelo gigantesco vínculo que criou com a pobreza no Brasil e, de outro, por seu estranhamento, como estrangeiro, intelectual e trabalhador social, dos modos de viver presente entre os pobres. Forte vínculo e estranhamento geraram intensa inquietude e pesquisa.

Em entrevista publicada na revista Trabalho, Educação e Saúde (Vasconcelos, 2005), Valla afirmava que, quando chegou ao Brasil como missionário católico, em 1964, ficou extremamente abismado com a pobreza: “Acreditava que, se eu não podia fazer nada, podia pelo menos conviver com o problema” (p. 228229). Mobilizado com a pobreza e dela se aproximando muito, começou, aos poucos, a se aproximar também de pessoas da esquerda. Diferentemente, de muitos missionários estrangeiros dessa época, não foi morar entre os pobres; dedicou-se à aproximação com as instituições públicas, assistenciais e acadêmicas dedicadas à questão social. Com sua mente de estrangeiro, estranhou esses dois universos e passou a investir na busca de esclarecimentos de facetas das frequentes incompreensões com que deparava entre intelectuais e trabalhadores sociais a respeito da vida dos pobres, principalmente daqueles vivendo na periferia dos grandes centros urbanos. Assim, grande número de seus textos dos últimos dez anos parte da afirmação de José de Souza Martins, que frequentemente citava, de que a propalada crise dos movimentos sociais e das iniciativas populares é, antes de tudo, uma crise de compreensão dos intelectuais e trabalhadores sociais (mesmo aqueles de esquerda) sobre o que realmente está acontecendo entre os pobres. A partir daí, dedicouse a estudar diferentes aspectos da cultura popular que geram incompreensões.

Seu vínculo com a pobreza é intenso. Nesses últimos anos, em que lutou bravamente contra as pesadas limitações trazidas pela doença, Victor passou a reconhecer com clareza e a explicitar a centralidade desse vínculo na estruturação de sua vida. Diferencia-se, assim, de grande número dos intelectuais de esquerda que estudam os pobres ou organizam intervenções sobre eles sem com eles se envolverem. Mesmo quando os convites para palestras e as demandas acadêmicas por orientação, na pós-graduação, se tornaram intensos, fazia questão de manter sua rotina de visitas e trabalhos na região da Leopoldina, no Rio de Janeiro. Essa atitude muito influenciou sua produ- 
ção teórica. Seus textos acadêmicos provocaram, por muito tempo, desdém entre alguns dos seus colegas pesquisadores da Escola Nacional de Saúde Pública da Fundação Oswaldo Cruz, onde trabalhava, pois não partia ou valorizava centralmente ideias presentes em bibliografias estrangeiras de autores da moda. Mas a impressionante repercussão de suas reflexões, indicada, por exemplo, pela grande frequência com que seus textos são referidos e citados em outros estudos, foi modificando esse quadro.

Seus textos acadêmicos nasceram dessa imersão emocionada e militante no mundo popular. Apontam para a força criativa, também na academia, desse processo engajado de produção de saber, tão presente nas práticas de educação popular. Esse tipo de produção teórica já é frequente entre outros educadores populares, mas encontrou em Valla reconhecimento e valorização acadêmica que muito o legitimaram.

Nesse sentido, a presença e a liderança de Victor Valla do GT Educação Popular muito contribuíram para impedir que certa erudição pernóstica, bastante presente nas instituições acadêmicas, não prevaleça. Um pouco da forma compartilhada e amorosa de produção de saberes da educação popular passou a estar mais presente no modo de ser desse grupo de trabalho. A sua coragem de trazer para o ambiente de pesquisa as inseguranças, perplexidades e os dilemas de pesquisador apontava para uma dimensão metodológica importante da educação popular, diferenciando-a de outras propostas pedagógicas centradas na problematização. Valla não é um intelectual que reflete sobre educação popular, mas um educador popular que produz academicamente. Sempre encarou a produção textual como parte da luta política para a superação das injustiças sociais.

Outro elemento importante para compreender a sua produção acadêmica é a grande importância de sua forte capacidade intuitiva na estruturação de suas reflexões. Na sua convivência com as instituições públicas de um lado e, de outro, com o mundo popular, ele ficava incomodado e instigado por algumas incompreensões, até que lhe ocorria uma ideia que oferece uma chave interpretativa para desvendá-las.
Inicialmente eram ideias pouco claras. Passava a conversar insistentemente com alguns companheiros sobre essa percepção, o que passava a ser quase uma obsessão. Nesse momento, ele se tornava repetitivo. Aos poucos, essas ideias iam se tornando mais claras. A sistematização acadêmica vinha depois. Por isso, ele se apegava muito a um pequeno número de interlocutores. Havia uma forte participação coletiva na organização das reflexões, mas a fonte primeira de seus textos era a percepção intuitiva. O diálogo com outros autores, a escrita e o retorno dos leitores iam ajudando-o a precisar suas reflexões. Nesse sentido, os textos de Valla sucedem-se em um movimento espiral. O texto seguinte repete muitos elementos do anterior, mas acrescenta novos elementos e esquece outros. Essa forte repetição de muitas ideias em textos que se seguem causa alguma perplexidade em que o acompanha por pouco tempo. Era a forma que tinha de refinar sua reflexão em um movimento contínuo, disciplinado e quase obsessivo. É preciso ter acesso a textos distantes cronologicamente para perceber a força criativa de seu método.

Esse modo de trabalhar academicamente foi aprendido na sua convivência com o meio popular. Valla veio de uma família norte-americana de classe média bastante seca afetivamente em suas relações. Ao chegar ao Brasil, ficou fascinado com a alegria, a forma emocionada de viver e se relacionar presentes no mundo popular. Ficou muito cativado. Aos poucos, foi deixando que esse jeito emocionado e também cheio de oscilações fosse impregnando sua vida privada e profissional. Assim, sua relação com o trabalho social e acadêmico não foi apenas orientado por um compromisso ético e político racional; havia uma forte paixão na sua organização. Foi justamente essa ligação apaixonada com a causa dos pobres que lhe possibilitou um estado mental propício para a emergência de suas fortes intuições. Na minha longa convivência com Valla, talvez o maior aprendizado que tive foi perceber a legitimidade e produtividade acadêmica dessa forma pouco comum de gerir e organizar a produção teórica que acompanhei de perto. Trata-se de uma forma de organizar a produção de 
saber muito presente nas práticas locais de educação popular.

\section{Referência bibliográfica}

VASCONCELOS, Eymard Mourão. Entrevista: Victor Valla. Trabalho, Saúde e Educação, v. 3, n. 1, p. 227-238, 2005.

\section{Unidade entre pensamento e ação}

Eveline Bertino Algebaile

Universidade do Estado do Rio de Janeiro, Faculdade de Formação de Professores

Conheci o professor Victor Valla em 1991, por ocasião da $14^{a}$ Reunião da ANPEd, e desde então meu contato com seu pensamento vem se dando a partir de diferentes âmbitos: o GT de Educação Popular, a militância político-partidária, o acompanhamento de políticas públicas de saúde e educação, seu trabalho no Centro de Estudos e Pesquisas da Leopoldina (CEPEL), suas aulas e seus textos, nossos estudos sobre pobreza no Brasil, coordenados por ele e por seu inseparável amigo Eduardo Stotz, sua orientação em meu doutorado, as conversas soltas sobre a vida.

Dessa forma de contato, trago a impressão de que suas contribuições ao campo da educação popular devem ser compreendidas a partir do que está explicitado em seus textos e suas falas e do que às vezes está apenas inscrito em seu modo de atuar. Tomando emprestada uma formulação de Gramsci (2000), diria que Valla produziu uma espécie de conhecimento “em ato”, em profunda unidade com o seu pensamento registrado em textos, mas nem sempre totalmente aí explicitado. É sobre esse modo de conhecimento que gostaria de falar, pois acho que tem particular importância no campo da educação popular.

Ao assumir, em profundidade e para a vida inteira, o desafio de conhecer as classes populares no Brasil - com atenção para sua situação de exploração e destituição, mas também às suas formas de responder a essa situação e às suas possibilidades de propor e produzir caminhos de sentido diverso do instituído -
Valla envolveu-se com os “modos de conhecer” irredutíveis à esfera específica das atividades de pesquisa e da interlocução acadêmica. Modos de conhecer que atravessam um campo muito mais vasto, envolvendo um amplo e complexo conjunto de práticas e relações implicadas com atividades profissionais, políticas e sociais.

Nessa busca da compreensão das classes populares em ação, ele não hesitou em se debruçar sobre temas diversos - favela, saúde, educação escolar, religiosidade popular -, assumindo os riscos de trafegar por áreas distintas que, como sabemos, têm seus acúmulos, seus códigos, suas disputas e, portanto, seus critérios - por vezes implacáveis - de reconhecimento. Essa “mudança de área”, prática comumente desaconselhada no campo acadêmico e, no entanto, teimosamente enfrentada por Valla com desprendimento incomum, dá visibilidade, de meu ponto de vista, a um aspecto muito importante desse "conhecimento em ato”.

A atenção máxima às questões concretas que, em cada contexto, permitem melhor apreender as classes populares em ação indica uma compreensão radical de que conhecer o outro implica imergir em sua realidade até o ponto de reconhecer a validade da pauta de questões ali produzida. Nos termos trabalhados pelo próprio Valla, exige uma “conversão” à experiência do outro e ao reconhecimento de sua legitimidade para indicar novos territórios de investigação, para indicar caminhos de ação.

Penso que esse desprendimento tem papel fundamental na produção de uma teoria da ação das classes populares capaz de problematizar vigorosamente as noções de direitos e de participação social predominantes no debate sobre desigualdades sociais no Brasil. Trafegar por distintos lugares de destituição possibilitou ao professor Valla a percepção refinada dos vínculos entre práticas, ações e relações que, vistas isoladamente, podem não parecer significativas, porém, apreendidas em seus nexos, evidenciam-se como dispositivos que, além de reforçar desigualdades, constroem o terreno sobre o qual são produzidas cotidianamente formas graves de desautorização 
intelectual, moral e política das classes populares, a partir das quais são sistematicamente interditadas suas tentativas de intervenção no curso das políticas e práticas que lhes sequestram direitos.

Há, no pensamento e nas ações de Valla, uma concepção inconformista de público que afirma incondicionalmente a participação de todos os segmentos sociais nos processos que resultam em definição de noções e de formas de exercício de direitos. É uma concepção que recusa pesos e medidas diferenciados para os diversos grupos sociais e que, no entanto, não se assenta em idealizações da participação popular. Entendo assim porque ele não lamenta os limites à participação popular a partir da ausência ou presença atenuada das classes populares nos conselhos ou nas práticas político-partidárias, por exemplo. Seu ponto de partida são as práticas participativas mais banais, como a participação difusa nas relações escolares e nas tentativas de acesso ao atendimento à saúde, em que formas diversas de cassação da fala e de interdição de ações são realizadas sistematicamente sem que, no entanto, seja totalmente visível essa sistematicidade e sem que percebamos as formas capilares de nossa adesão ou consentimento a essa matriz de ação.

Há, aqui, uma concepção de público que não se destina a ser venerada como utopia, mas a ser exercida no tempo presente, sustentando desde já a reconstrução profunda das condições de participação dos sujeitos na produção histórica das noções e das formas de exercício de direitos. Participar é participar, por qualquer meio, pelos meios disponíveis, por todos os meios. É um jogo em que não cabem prévias nem ensaios. $\mathrm{O}$ “aquecimento” é a própria ação.

Essa concepção de público, para Valla, não é um princípio a ser aplicado normativamente sobre as práticas. É conhecimento em ato, encarnado em ações e indissociável delas. Quase inexplicável, seu modo de se fazer compreensível é realizar-se. Inscrita na própria prática e por ela formulada, essa concepção resulta em instigantes interrogações sobre as formas de organização institucional vigentes e nossa disposição para pensar e exercitar possibilidades de um fazer institucional de novo tipo, referenciado no aproveitamento de possibilidades e fissuras nos modos de funcionamento das instituições para fomentar agregações, invenções, derivas e coesões que, novamente lembrando Gramsci, possam se tornar matrizes de novas modificações.

Penso que é a partir dessa forma "prática" de formular essa compreensão de público que Valla não cai na tentação de difundi-la por meio de prescrições. Trata-se, de seu ponto de vista, de viabilizá-la por meio da refundação compartilhada de práticas e objetivos públicos e, portanto, da disposição para, lembrando uma expressão do poeta Manoel de Barros, "voar fora da asa”.

Esse é um movimento visível, por exemplo, nas suas próprias tentativas de uso da estrutura e das prerrogativas institucionais da academia para ampliar seus vínculos com “a rua”, com os espaços onde a vida transcorre a partir de referências diversas o suficiente para provocar estranhamentos que abalem certezas e fazeres fossilizados; na sua opção rigorosa por orientar estudos vinculados à pesquisa social orgânica; no seu empenho em disseminar práticas e valores que, por vezes, correm na contramão de exigências acadêmicas bastante consagradas; nas suas insistentes práticas de alargamento e recriação de campos de interlocução, envolvendo a valorização da participação em espaços não polarizados pelas regras, valores e formas de prestígio acadêmico, a reconstrução de modos de ver e de ouvir o que não se conhece e a busca de modos de falar e escrever que não circunscrevam a produção científica a um campo de iniciados.

Ao longo de sua história de trabalho, essas disposições e esses modos de conhecer encarnam diversas ações e delas se desdobram. A criação do Centro de Estudos e Pesquisas da Leopoldina (CEPEL), que atuou por de dez anos nessa área suburbana do Rio de Janeiro intensamente ocupada por favelas e conjuntos habitacionais populares, é exemplar desse caso. Aproximando professores e estudantes universitários, profissionais de políticas públicas, militantes políticos, parlamentares, moradores da região, movimentos sociais e igrejas, o CEPEL funcionou quase como um "partido”, na concepção larga dada ao termo por Gramsci, constituindo-se como espaço de agregação 
de diferentes ações e sujeitos, de produção de conhecimentos a partir do encontro entre modos de conhecer diversos e de difusão desses conhecimentos por meios e formas inusitadas.

Também exemplares são suas proposições de metodologias de pesquisa que funcionam como verdadeiros programas de ação, desarranjando modos instituídos de abordagem dos “objetos” por meio da produção de contextos de investigação em que as falas cassadas e as ações interditadas ganham condições de expressão, provocando formas inéditas de interlocução, em que, tal como discutido por Vera Telles (2001), os aparentes dramas individuais passam a ser percebidos como problemas da vida pública do país. É o caso da Ouvidoria Coletiva, que funda espaços concretos de elaboração coletiva de problemas públicos vividos a partir de pontos de vista diferentes, por diversos segmentos de profissionais e de usuários.

Seria possível, nessa linha, lembrar seu empenho em se fazer presente nos espaços de formação de profissionais do campo social, interpelando as tendências à reprodução cotidiana de ações que intensificam a apartação das classes populares em relação aos direitos; atuando no enfrentamento dos distanciamentos entre profissionais e usuários de serviços referidos a direitos; exercitando a formação profissional para além das práticas institucionais manifestamente dirigidas a esse fim, construindo espaços de encontro que disputem com as condições institucionais vigentes os sentidos da ação desses profissionais, garantindo-lhes referências sociais sólidas, implicadas com a produção compartilhada de objetivos públicos. Seria possível muito mais: lembrar sua renovada disposição para a participação partidária; sua história de participação em conselhos de políticas públicas; suas contribuições à constituição de redes de movimentos sociais...

Mas essa é a história de um construtor de possibilidades de agregações, o que significa que é uma história que atravessa muitos de nós. Sendo esse seu sentido e sua força, não cabe desejar esgotá-la em um texto, aprisionála em um ponto de vista. Cabe deixar que ela persista, sempre teimosa, a partir das agregações e derivas que a garantem como uma história em construção.
Referências bibliográficas

GRAMSCI, Antonio. Cadernos do cárcere. v. 3: Maquiavel. Notas sobre o estado e a política. Rio de Janeiro: Civilização Brasileira, 2000.

TELLES, Vera da Silva. Pobreza e cidadania. São Paulo: Editora 34, 2001.

\section{Problematizando o termo conversão a partir do campo religioso}

\author{
Victor Vincent Valla \\ Fundação Oswaldo Cruz, Escola Nacional de \\ Saúde Pública
}

Ao longo de mais de vinte anos participando do GT Educação Popular, compreendo que o objeto de conhecimento e de ação desse campo é a situação de exploração e subordinação das classes populares, sua apartação dos direitos já naturalizados para as classes médias e altas. Em torno desse objeto de conhecimento e de ação, temos construído concepções, práticas e propostas permanentemente postas à prova em termos do seu alcance efetivo, bem como de sua capacidade de indicar caminhos e de resultar em soluções para os problemas identificados. Por isso, nossa participação nesse campo deve também se dar no sentido de contribuir para a discussão e reconstrução dessas concepções e práticas, para que possamos avançar na identificação desses caminhos e na construção de novas condições a partir das quais seja possível produzir soluções verdadeiras.

Nessa perspectiva, uma das minhas maiores tentativas de contribuição a esse campo são meus estudos sobre religiosidade popular. Primeiro, porque entendo que o exercício da religiosidade é, em um país marcado por tantas desigualdades, como o nosso, uma experiência central na organização da vida das classes populares, uma espécie de experiência-síntese, a partir da qual as classes populares têm elaborado uma parte importante das suas relações com os sofrimentos que atingem suas vidas, sofrimentos materializados nos desafios de sobrevivência, como os relacionados às 
questões de moradia, saúde, educação escolar, violência e participação política.

Segundo porque esse é um tema sem prestígio nos debates sobre os enfrentamentos políticos do problema da pobreza, e o enfrentamento da pobreza exige que nos ocupemos dos temas sem prestígio para podermos conhecer o que não conhecemos, as práticas, ações e relações que costumamos achar que "não têm sentido", e que, no entanto, são referências sem as quais não podemos pensar em profundidade o mundo e as suas mudanças possíveis. A compreensão da centralidade da religiosidade popular é um caminho muito importante para avançarmos na compreensão das classes populares e de suas lutas. Por isso me dedico a ele.

A religiosidade popular é um campo vasto. Envolve uma multiplicidade de práticas e grande variedade de estudos realizados por pesquisadores de diferentes áreas, a partir de diferentes metodologias, destacandose estudos nos campos da sociologia e da antropologia que abordam as práticas de religiosidade pela ótica da cultura. Mas o entendimento da religiosidade como experiência articuladora das demais práticas e relações das classes populares exige, no meu entender, mais que metodologia de pesquisa; pede uma postura de imersão na realidade de vida a partir da qual a religiosidade adquire essa centralidade.

Minha opção por estudar o pentecostalismo decorre do entendimento de que é nesse movimento religioso que a centralidade da pobreza se dá de forma mais radical. Por isso, inclusive, o forte fluxo de adesão dos pobres, especialmente os muito pobres, a essa religião. Isso me dá garantias de me aproximar de um núcleo de práticas das classes populares em que significativas experiências dos pobres se evidenciam mais intensamente, o que permite o aprofundamento de questões que atravessam meus trabalhos há muito tempo, mas que ganharam uma de suas formas mais claras na discussão que tentei empreender sobre a "crise da compreensão”, que, para mim, permanece como um desafio intelectual e um desafio histórico.

É desse entendimento que também decorre meu interesse em discutir o termo conversão. Há cerca de cinco décadas, Richard Schaull, um pastor presbite- riano que atuou em países latino-americanos como missionário e professor, propôs que seminaristas, comumente da classe média, convivessem com as classes populares no seu lugar de moradia, a fim de melhor entender as formas de compreensão e ação daqueles para os quais se dirigiam as atividades missionárias. Para Schaull, esse ato de conviver com as classes populares em seu lugar de moradia seria uma forma de incorporar seu olhar para o mundo, e essa seria uma condição essencial para uma atuação verdadeiramente envolvida com o enfrentamento da situação de profunda desigualdade e sofrimento que marca o problema da pobreza nesses países. O termo usado por Schaull (César \& Schaull, 2001) para fazer referência a essa forma de ação foi conversão, mas segundo um significado não-convencional.

Em geral, o termo conversão é compreendido como passagem de uma crença para outra, de uma doutrina para outra. Também é comum entender-se que a conversão é a aceitação de uma missão indicada por Deus, a aceitação de um chamado divino. Schaull, porém, não entendia a conversão nesse sentido. Para ele, em sentido pleno, a conversão não pressupunha a crença em um Deus nem o atendimento a um chamado divino, mas a adoção de um novo lugar a partir do qual se poderiam compreender em profundidade os principais problemas para os quais buscamos soluções. Nesse sentido, Schaull indicou que, no mundo em que vivemos, a conversão, em sentido pleno, seria exclusivamente a conversão à questão da pobreza, ponto central para a discussão e enfrentamento de todos os demais problemas que hoje e no futuro nos desafiariam.

Acredito que a discussão do termo conversão a partir dessa perspectiva contribui de forma especial para a problematização dos nossos desafios de pensamento e de ação no campo da educação popular, no sentido de nos aproximarmos mais dos resultados históricos que desejamos.

Em um sentido convencional, ao longo da história, a ideia de conversão pode ser identificada, com sentidos diversos, em inúmeras propostas de ação nos campos religioso e político. No campo religioso, a 
ideia de conversão aos pobres aparece, por exemplo, com bastante nitidez, na religião católica, na fundação da Ordem Franciscana, destacando-se, porém nesse caso um sentido de renúncia ao mundo de opulência e riqueza. No campo político, também é possível identificar o princípio da conversão nas práticas de inserção de membros de organizações políticas nos espaços de vida e trabalho das massas populares. A ideia de conversão aí presente, porém, não pressupõe renúncia nem imersão na experiência de vida dos pobres, mas, na verdade, uma inserção popular de militantes políticos que, por meio de contatos cotidianos, tentam operar a conversão dos pobres a um projeto político elaborado fora daquele meio. São militantes que entram nos meios populares não para se modificar, mas para modificar os outros.

A ideia de Schaull à qual me refiro e que, de modo geral, é constituída dos mesmos princípios que orientaram a Teologia da Libertação, tem um elemento novo fundamental, implicado com questões não apenas políticas mas também epistemológicas de grande importância para o campo da educação popular: a ideia de que a conversão é um movimento de descentramento, uma mudança fundamental em termos do conjunto de experiências a partir do qual olhamos e entendemos o mundo, as possibilidades de ação no mundo e a construção de um mundo possível para todos.

Esse, como se vê, não é um movimento a ser esperado das classes populares, mas das classes médias, habituadas a entender sua experiência como central e a deduzir disso, de um lado, sua autoridade e capacidade para dispor sobre os problemas do mundo e, de outro, a permanente minoridade política e cultural das classes populares para dispor sobre as questões que afetam suas vidas. Tudo se passa como se o padrão de vida e de direitos das classes médias fossem extensíveis, sem mediações, para as classes populares, quando na verdade esses padrões resultam de formas históricas de utilização privilegiada de meios e recursos.

Acho importante lembrar aqui a discussão de Milton Santos sobre o conjunto de saberes práticos e valores produzidos às margens dos padrões de vida das classes médias pelos imensos segmentos da população submetidos à experiência da escassez. Com todos os problemas e degradações impostos aos pobres, os espaços de vida das classes populares têm sido o lugar de construção de uma experiência humana de repartição, compartilhamento e solidariedade capaz de indicar caminhos válidos para a transformação do mundo, incluindo-se aqui a urgência de enfrentamento de uma cultura de apropriação particularista e de esgotamento de todos os recursos naturais, econômicos e humanos que não é suficientemente problematizada em nosso meio.

Por essa ótica, a conversão - como movimento de confrontação de nossa experiência a partir do nosso submetimento à centralidade da experiência do outro, da tomada da experiência do outro como referência para pensar o mundo - propicia também uma conversão dos sentidos que estamos habituados a atribuir às coisas. Se a experiência a partir da qual penso o mundo é a experiência constituída nos contextos de escassez, noções já naturalizadas de direitos, urbanização, escolarização, justiça, modernização, iniciativa, conhecimento adquirem inevitavelmente novos delineamentos.

Não é o caso, certamente, de propormos a convivência com as classes populares na mesma forma proposta por Schaull. Sabemos das diferenças entre a prática profissional e a prática missionária. Mas devemos ter o máximo de atenção à construção de práticas que garantam uma relação profunda com a vida das classes populares, de forma que se compreenda o que é preciso fazer para que a educação popular não seja uma dentre outras formas de dizer ao outro o que fazer a partir de uma experiência histórica e de condições que lhe são estranhas.

\section{Referências bibliográficas}

CESAR, Waldo; SHAULL, Richard. Pentecostalism and the future of the Christian Churches: promises, limitations, and challenges. Grand Rapids: W. B. Eerdmans, 2001.

EYMARD MOURÃO VASCONCELOS, doutor em medicina tropical pela Universidade Federal de Minas Gerais (UFMG), 
com pós-doutorado em saúde pública na Fundação Oswaldo Cruz, é professor do Departamento de Promoção da Saúde e do Programa de Pós-Graduação em Educação da Universidade Federal da Paraíba (UFPB), no qual coordena o Grupo de Pesquisa Educação Popular em Saúde. Publicações recentes: Educação popular e a atenção à saúde da família (4. ed. São Paulo: Hucitec, 2008); A educação popular na atenção primária à saúde (Revista de Atenção Primária à Saúde, v. 11, n. 3, p. 344-345, jul./set. 2008); Para além do controle social a insistência dos movimentos sociais em investir na redefinição das práticas de saúde (In: FLEURY, Sonia; LOBARO, Lenaura de Vasconcelos C. (Orgs.). Participação, democracia e saúde. Rio de Janeiro: Centro Brasileiro de Estudos de Saúde, 2009. p. 270-288). Pesquisa atual: "Educação popular na formação universitária em saúde”.E-mail: eymard.vasconcelos@gmail.com

EVELINE BERTINO ALGEBAILE, doutora em educação pela Universidade Federal Fluminense (UFF), é professora adjunta de políticas públicas e educação da Faculdade de Formação de Professores da Universidade do Estado do Rio de Janeiro (UERJ). Publicações recentes: Escola pública e pobreza no Brasil: a ampliação para menos (Rio de Janeiro: Lamparina/FAPERJ, 2009); Sentidos da arte na educação escolar (In: GARCIA, Regina Leite. (Org.). A formação da professora alfabetizadora: reflexões sobre a prática. 5. ed. v. 1. São Paulo: Editora Cortez, 2008. p. 200-220); Expansão metropolitana, erosão da esfera pública e novas exigências sociais de governabilidade (Scripta Nova, Barcelona, v. XI, n. 43, p. 1-13, 2007). Pesquisa atual: "Política social e educação no contexto de ajuste do Estado: características organizacionais e implicações sociais da recomposição setorial em curso no Brasil”. E-mail: eveline@prolink.com.br

MARIA TEREZA GOUDARD TAVARES, doutora em educação pela Universidade Federal do Rio de Janeiro (UFRJ), é professora adjunta no Departamento de Educação e do Mestrado em Educação da Faculdade de Formação de Professores da Universidade do Estado do Rio de Janeiro (UERJ), pesquisadora do Procientista da UERJ/Fundação de Amparo à Pesquisa do Estado do Rio de Janeiro (FAPERJ) e membro do GT de Educação Popular desde 1996. Publicações recentes: organizou com PEREZ, Carmem Lúcia Vidal; ARAÚJO, Mairce da Silva; ALVARENGA, Marcia Soares de et al. Memórias e patrimônios: experiências em formação de professores (Rio de Janeiro: EDUERJ, 2009);
SAMPAIO, Carmen Sanches; GARCIA, Regina Leite. Conversas sobre o lugar da escola (Rio de Janeiro: HP Comunicação Editora e Profedições, 2006); Os “pequenos” e a cidade: o papel da escola na construção do direito à cidade (Contexto \& Educação, v. 1, p. 69-92, 2007). Pesquisa atual: "Poder local, direito à cidade e formação de professoras da infância em periferias urbanas”. E-mail: mtgtavares@yahoo.com.br

REINALDO MATIAS FLEURI, doutor em educação pela Universidade Estadual de Campinas (UNICAMP), com pós-doutorado na Universitá di Perugia (Itália) e na Universidade de São Paulo (USP), é professor titular no Centro de Ciências da Educação da Universidade Federal de Santa Catarina (UFSC) e coordenador do Núcleo de Pesquisa Mover - Educação Intercultural e Movimentos Sociais, na Universidade Federal de Sergipe (UFS), no qual desenvolve o projeto integrado de pesquisa "Educação intercultural: desconstrução de subalternidades em práticas educativas e socioculturais", financiado pelo Conselho Nacional de Desenvolvimento Científico e Tecnológico (CNPq). Últimas publicações: Universidade e educação popular (Florianópolis: NUP/CED/UFSC, 2001); Educar para quê? (9. ed. São Paulo: Cortez, 2001); Educação intercultural: mediações necessárias (Rio de Janeiro: DP\&A, 2003); Disciplina e rebeldia na escola: olhar da complexidade (Brasília: Liberlivros, 2008).E-mail: rfleuri@terra.com.br

VICTOR VINCENT VALLA, doutor em história social peal Universidade de São Paulo (USP) e pós-doutorado na University of Califórnia - Berkeley, nos Estados Unidos, era professor titular da Escola Nacional de Saúde Pública (ENSP/Fiocruz) e professor do Programa de Pós-Graduação em Educação da Universidade Federal Fluminense (UFF). Últimas publicações: Movimentos sociais, educação popular e intelectuais: entre algumas questões metodológicas. (In: FLEURI, Reinaldo Matias (Org.). Intercultura e movimentos sociais. Florianópolis: Mover/NUP, 1998a. p. 187-200); A revalorização da educação popular numa conjuntura de crise (In: REUNIÃO ANUAL DA ANPEd, 21., Caxambu, 1998. Anais... Rio de Janeiro: ANPEd, 1998. 1. CD-ROM); Apoio social e saúde: buscando compreender a fala das classes populares (In: COSTA, Marisa Vorraber (Org.). Educação popular hoje. São Paulo: Loyola, 1998, p. 151-179); Pobreza, emoção e saúde: uma discussão sobre o pentecostalismo no Brasil (Revista Brasileira de Educação, n. 19, p. 63-75, 2002). 